\title{
DNA Replication Inhibition
}

National Cancer Institute

\section{Source}

National Cancer Institute. DNA Replication Inhibition. NCI Thesaurus. Code C40828.

DNA Replication Inhibition involves interference with, or restraint of, the activities of biologic molecules or complexes involved in the process by which the two strands of a DNA double helix separate and each strand acts as a template for the synthesis of a complementary strand by specific base pairing. 